\title{
Evaluating Cefiderocol in the Treatment of Multidrug-Resistant Gram-Negative Bacilli: A Review of the Emerging Data
}

This article was published in the following Dove Press journal: Infection and Drug Resistance

\author{
Daniele Roberto Giacobbe, (iD) ${ }^{1,2}$ \\ Eugenio Ciacco, ${ }^{3}$ \\ Corrado Girmenia, (iD ${ }^{4}$ \\ Federico Pea, 5,6 \\ Gian Maria Rossolini, ${ }^{7,8}$ \\ Giovanni Sotgiu, (D) ${ }^{9}$ Carlo Tascini, ${ }^{10}$ \\ Mario Tumbarello, ${ }^{11,12}$ \\ Pierluigi Viale, ${ }^{5,6}$ Matteo Bassetti ${ }^{1,2}$ \\ On behalf of the ISGRI-SITA (Italian \\ Study Group on Resistant Infections \\ of the Italian Society of Anti-infective \\ Therapy)
}

'Clinica Malattie Infettive, Ospedale Policlinico San Martino - IRCCS, Genoa, Italy; ${ }^{2}$ Department of Health Sciences, University of Genoa, Genoa, Italy; ${ }^{3}$ Pharmacy Unit, S. Salvatore Hospital, ASLI

Abruzzo, L'Aquila, Italy; ${ }^{4}$ Hematology,

Dipartimento Medicina Traslazionale e di Precisione, AOU Policlinico Umberto I, Sapienza University of Rome, Rome, Italy; ${ }^{5}$ Department of Medical and Surgical Sciences, Alma Mater Studiorum, University of Bologna, Bologna, Italy; ${ }^{6}$ University Hospital IRCCS Policlinico Sant'Orsola Bologna, Bologna, Italy; ${ }^{7}$ Department of Experimental and Clinical Medicine, University of Florence, Florence, Italy; ${ }^{8} \mathrm{Clinical}$ Microbiology and Virology Unit, Florence Careggi University Hospital, Florence, Italy; ' Department of Medical, Surgical and Experimental Sciences, University of Sassari, Sassari, Italy; ${ }^{10}$ SOC Malattie Infettive, Azienda Sanitaria Integrata, University of Udine, Udine, Italy; " 'Dipartimento di Scienze di Laboratorio e Infettivologiche, Fondazione Policlinico Universitario A. Gemelli IRCCS, Rome, Italy; ${ }^{12}$ Dipartimento di Sicurezza e Bioetica, Università Cattolica del Sacro Cuore, Rome, Italy

Correspondence: Daniele Roberto Giacobbe

Clinica Malattie Infettive, Ospedale Policlinico San Martino - IRCCS, L.go

R. Benzi 10, Genoa 16132, Italy

Tel +390105554658

Email daniele.roberto.giacobbe@gmail.com

\begin{abstract}
Infections due to multidrug-resistant Gram-negative bacteria (MDR-GNB), especially when carbapenem resistant, have been very difficult to manage in the last fifteen years, owing to the paucity of dependable therapeutic options. Cefiderocol is a siderophore cephalosporin recently approved by the Food and Drug Administration (FDA) and European Medicines Agency (EMA) that may have the potential to fill some of the remaining gaps in the treatment of MDR-GNB infections. Among others, cefiderocol demonstrated in vitro activity against carbapenem-resistant Acinetobacter baumannii and metallo- $\beta$-lactamases producers. Clinical data from both registrative studies and post-marketing experiences are essential to confirm whether these promises from in vitro studies could readily translate into clinical practice, as well as to delineate the precise place in therapy for cefiderocol for the treatment of MDR-GNB in the near future. Because of its unique potential, it is essential to provide both randomized controlled trials (RCT) and real-life data to improve the ability of clinicians to exploit its benefit in both empirical and targeted treatment of MDR-GNB infections. In this narrative review, we discuss the emerging data from pivotal RCT and initial real-life experiences on the use of cefiderocol for the treatment of MDR-GNB infections.
\end{abstract}

Keywords: cefiderocol, siderophore, Pseudomonas, Acinetobacter, Enterobacterales, antimicrobial resistance

\section{Introduction}

Infections due to multidrug-resistant Gram-negative bacteria (MDR-GNB), especially when carbapenem resistant, have been very difficult to manage in the past fifteen years, owing to the paucity of therapeutic options. ${ }^{1-5}$ Furthermore, available options such as polymyxins, aminoglycosides, and/or glycylcyclines, although certainly useful in presence or resistance to all other classes, have some disadvantages that clinicians would like to avoid, including nonnegligible toxicity and possible suboptimal pharmacokinetics in some sites of infection. ${ }^{6-8}$

Some precious additions to the antibiotic armamentarium such as ceftazidime/ avibactam, ceftolozane/tazobactam, meropenem/vaborbactam, and imipenem/relebactam have recently allowed to renew the availability of $\beta$-lactam antibiotics (that usually display good safety profiles and pharmacokinetics) for treating some MDRGNB. $^{9-12}$ However, some gaps still need to be filled, for example, restoring the activity of $\beta$-lactams against metallo- $\beta$-lactamases (MBL)-producing GNB and carbapenem-resistant Acinetobacter baumannii.

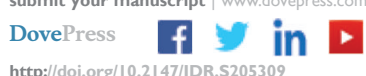


In this narrative review, we discuss the available antimicrobial, pharmacological, and clinical data for cefiderocol, a siderophore cephalosporin recently approved by the Food and Drug Administration (FDA) and European Medicines Agency (EMA) that may have the potential to fill some of the remaining gaps in the treatment of MDRGNB infections.

\section{Methods}

The structure of the present narrative review was agreed by all authors and articulated in the following sections: (i) antimicrobial properties; (ii) pharmacological properties; (iii) results of randomized clinical trials: efficacy; (iv) safety of cefiderocol; (v) case reports and case series; (vi) place in therapy. Then, the authors were divided in small groups in order to draft the different sections, supported by inductive PubMed searches for relevant publications. Eventually, the different drafts were merged into a final manuscript that was approved by all authors.

\section{Antimicrobial Properties}

Cefiderocol is a novel siderophore cephalosporin active against GNB, including strains of Enterobacterales and nonfermenters that exhibit difficult-to-treat (DTR) resistance phenotypes (ie, resistant to fluoroquinolones and older $\beta$-lactams including carbapenems). ${ }^{13,14}$ This notable and thus far unique spectrum of activity is dependent on the following features: i) uptake across the bacterial outer membrane also via iron transporters, thus enhancing accumulation of the drug in the periplasmic space and overriding resistance mechanisms such as efflux pumps and porin alterations; and ii) remarkable stability, likely conferred by modifications in the C-7 and C-3 side chains, against all classes of beta-lactamases, including carbapenemases (both serine carbapenemases, such as KPC and OXA-types, and metalloenzymes such as NDM, VIM, IMP and the intrinsic L1 carbapenemase of Stenotrophomonas maltophilia). ${ }^{15-18}$

Similar to cefepime, cefiderocol carries a pyrrolidinium group on the $\mathrm{C} 3$ side chain, which enhances stability to $\beta$ lactamases and antimicrobial activity. Moreover, similar to ceftazidime, cefiderocol carries an aminothiazole ring and a carboxypropyl-oxyimino group on the C7 side chain, which also enhances stability to $\beta$-lactamases and activity against Gram-negative bacilli, including Pseudomonas aeruginosa. In addition, cefiderocol harbors a chlorocatechol group at the end of the C3 side chain, which is able to chelate ferric iron and confers siderophore activity: the complex cefiderocol- $\mathrm{Fe}^{3+}$ can thus be actively transported into the periplasmic space by specific irontransporters, such as PiuA in P. aeruginosa, unlike other beta-lactams which only enter by passive diffusion across porin channels. ${ }^{14,18}$ Indeed, resistance acquisition studies revealed that mutations causing increased levels of pyoverdine production or higher level of FecA expression (both involved in the iron transport system) were associated with increased cefiderocol minimum inhibitory concentration (MIC) values in P. aeruginosa. ${ }^{19}$ Once in the periplasmic space, cefiderocol exerts its antimicrobial activity by inhibition of the penicillin-binding proteins (PBP)-mediated cell wall synthesis, leading to cell death. ${ }^{14,18}$ Cefiderocol was shown to have high affinity for PBP3 in clinically relevant Gram-negative rods (eg, Klebsiella pneumoniae, Escherichia coli, P. aeruginosa, and Acinetobacter baumannii), and also for PBP2 in K. pneumoniae and for PBP1a in P. aeruginosa. ${ }^{20,21}$

Similar to cefepime, cefiderocol is a weak AmpC inducer (possibly due to low PBP4 binding) with low affinity for chromosomal AmpC-type $\beta$-lactamases, ${ }^{22}$ which account for its overall good activity also against AmpC overproducing strains. Mutations causing alteration or loss of porin channels, such as OmpK35 and OmpK36 in $K$. pneumoniae, are associated with a marginal decrease of cefiderocol antimicrobial activity, ${ }^{18}$ while inactivation of the MexAB-OprM efflux pump only causes a slight cefiderocol MIC decrease in $P$. aeruginosa, suggesting that this mechanism is unable to efficiently expel the molecule outside the microbial cell. ${ }^{20}$

During infections, an iron depleted-milieu is expected to be encountered in the host tissues in response to which the bacterial iron transporters are up-regulated. ${ }^{23}$ This should be accounted for when testing in vitro susceptibility to cefiderocol, which must be carried out using iron-depleted media when using reference broth microdilution. The growth medium is prepared by treating conventional cationadjusted Mueller-Hinton broth with a cation-binding resin in order to remove all the cations, and subsequently replenishing the cation-depleted broth with adequate concentrations of $\mathrm{Mg}^{2+}, \mathrm{Zn}^{2+}$ and $\mathrm{Ca}^{2+} \cdot{ }^{24-26}$

For cefiderocol, the Clinical and Laboratory Standards Institute (CLSI) has set clinical breakpoints (CB) for Enterobacterales, $P$. aeruginosa, S. maltophilia, and A. baumannii, with MIC values of $\leq 4,8$, and $\geq 16 \mathrm{mg} / \mathrm{L}$ for susceptible, intermediate, and resistant categories, respectively. $^{24}$ However, these breakpoints were not accepted by FDA for A. baumannii and S. maltophilia, 
since these two species were not included in the ApeksUTI clinical trial that was designed for the approval of the drug in the USA. ${ }^{27}$ In Europe, the European Committee on Antimicrobial Susceptibility Testing (EUCAST) has set cefiderocol CB with MIC values of $\leq 2 \mathrm{mg} / \mathrm{L}$ and $>2 \mathrm{mg} / \mathrm{L}$ for susceptible and resistant categories, respectively, for both Enterobacterales and Pseudomonas spp., and also apharmacokinetic/pharmacodynamic (PK/PD) breakpoint MIC value of $\leq 2 \mathrm{mg} / \mathrm{L}$ for susceptibility, while CB was not set for $A$. baumannii and S. maltophilia due to insufficient clinical evidence. ${ }^{25}$ Epidemiological cut-off (ECOFF) values were also defined by the EUCAST as follows: $0.25 \mathrm{mg} / \mathrm{L}$ for E. coli, K. pneumoniae, and A. baumannii; $0.5 \mathrm{mg} / \mathrm{L}$ for P. aeruginosa, and $0.06 \mathrm{mg} / \mathrm{L}$ for $S$. maltophilia. ${ }^{25}$

Cefiderocol susceptibility has been investigated in large international surveillance studies carried out since 2014 (SIDERO-WT studies), covering over 28,000 Gramnegative isolates. ${ }^{13}$ Overall, the $\mathrm{MIC}_{90}$ for Enterobacterales (including E. coli, Klebsiella spp., Citrobacter spp., Enterobacter spp., Serratia spp., Morganella morganii, and Proteus spp.) ranged from 0.25 to $1 \mathrm{mg} / \mathrm{L}$, with no significant geographical or temporal differences. Cumulative activity against Enterobacterales from surveillance studies revealed that $>98 \%$ and $>99 \%$ of isolates were inhibited at concentrations of $2 \mathrm{mg} / \mathrm{L}$ and $4 \mathrm{mg} / \mathrm{L}$, respectively. Activity was retained against most isolates resistant to expanded-spectrum cephalosporins and carbapenems, including those producing different types of serine carbapenemases and metallo- $\beta$-lactamases. The $\mathrm{MIC}_{90}$ of Enterobacterales was $2-16 \mathrm{mg} / \mathrm{L}$ for strains producing different types of carbapenemases (Table 1). Against 1022 carbapenem-nonsusceptible Enterobacterales, of which $23 \%$ ceftazidime/avibactam resistant and $22 \%$ colistin resistant, cefiderocol $\mathrm{MIC}_{90}$ was $4 \mathrm{mg} / \mathrm{L}$ and $97 \%$ of the isolates were inhibited at a concentration of $4 \mathrm{mg} / \mathrm{L}{ }^{28}$

Data for Gram-negative nonfermenters from the international surveillance studies (see Table 1) reported $\mathrm{MIC}_{90}$ values of $0.5-2 \mathrm{mg} / \mathrm{L}$ for $P$. aeruginosa, $1-2 \mathrm{mg} / \mathrm{L}$ for Acinetobacter spp., $0.25-0.5 \mathrm{mg} / \mathrm{L}$ for S. maltophilia, and $0.12-0.5 \mathrm{mg} / \mathrm{L}$ for Burkholderia cepacia complex, underscoring the remarkable activity of cefiderocol against these difficult-to-treat pathogens. Cumulative activity data revealed that $>99 \%,>95 \%$, and $>95 \%$ of isolates of P. aeruginosa, A. baumannii, and B. cepacia complex from surveillance studies, respectively, were inhibited at a concentration of $4 \mathrm{mg} / \mathrm{L}$, while $>99 \%$ of isolates of S. maltophilia were inhibited at a concentration of $2 \mathrm{mg} /$
L. Activity was retained against most $P$. aeruginosa isolates resistant to carbapenems ( $>98 \%$ inhibited at $2 \mathrm{mg} / \mathrm{L}$ ), including those resistant to ceftolozane/tazobactam and producing metalloenzymes. A notable activity was also retained against carbapenem-resistant $A$. baumannii, with an $\mathrm{MIC}_{90}$ of $1 \mathrm{mg} / \mathrm{L}$ for isolates producing OXA-type carbapenemases (Table 1).

Few isolates with elevated cefiderocol MIC values ( $\geq 8 \mathrm{mg} / \mathrm{L}$ ) were detected from large surveillance studies. Some of these isolates were NDM- 1 metallo- $\beta$-lactamase or PER-1 extended-spectrum $\beta$-lactamase producers; in such cases, the addition of enzyme inhibitors (eg, dipicolinic acid and/or avibactam) was capable of reducing cefiderocol MIC values, suggesting that production of these $\beta$-lactamases may contribute to increased cefiderocol MICs. However, cefiderocol exhibited good activity against several isolates producing these enzymes, ${ }^{29}$ suggesting that the presence of additional resistance mechanisms is likely necessary to increase MIC values above the susceptibility breakpoint.

Concerning other pathogens, cefiderocol was shown to be active in vitro against Vibrio spp. Haemophilus influenzae, Moraxella catarrhalis, and Bordetella parapertussis, ${ }^{20}$ and also against less common Gramnegative pathogens including Pantoea spp., Sphingomonas paucimobilis, and Elizabethkingia meningoseptica. ${ }^{30}$ On the other hand, activity is variable against anaerobes, likely due to the variable importance of the siderophore-iron transport systems for growth under anaerobic conditions. ${ }^{20}$

In conclusion, cefiderocol is a new antibiotic with a unique mechanism of cell entry in Gram-negative pathogens, while being stable to most beta-lactamases. It is a potentially useful drug for treating infections caused by carbapenemase-producing Enterobacterales and nonfermenters. As such, cefiderocol appears to be one of the most innovative antibiotics among those recently approved.

\section{Pharmacological Properties Pharmacokinetic Properties}

The pharmacokinetic profile of cefiderocol was studied in healthy subjects both after single-ascending dose (100 to $1000 \mathrm{mg}$ ) and multiple-ascending dose (1000 $\mathrm{mg}$ q8h and $2000 \mathrm{mg} \mathrm{q} 8 \mathrm{~h}) .{ }^{31}$ Overall, cefiderocol showed a linear pharmacokinetic behavior with ascending doses and a mean elimination half-life of 2.0-2.7h. The mean total clearance was of 4.6-6.0 L/h and the fraction excreted unchanged 
Table I Susceptibility to Cefiderocol of Gram-Negative Isolates from Selected Surveillance Studies

\begin{tabular}{|c|c|c|c|c|c|c|c|}
\hline \multirow[t]{2}{*}{ Order/Genus/Species ${ }^{\mathbf{a}}$} & \multirow{2}{*}{$\begin{array}{l}\text { (No. } \\
\text { Isolates) }\end{array}$} & \multirow[t]{2}{*}{ Source $^{\mathrm{b}}$ (Years) } & \multicolumn{2}{|l|}{ MIC (mg/L) } & \multirow{2}{*}{$\begin{array}{l}\% \text { Inhibited at } \\
4 \mathrm{mg} / \mathrm{L}^{\mathrm{c}}\end{array}$} & \multirow{2}{*}{$\begin{array}{l}\% \text { Inhibited at } \\
2 \mathrm{mg} / \mathrm{L}^{\mathrm{d}}\end{array}$} & \multirow[t]{2}{*}{ References } \\
\hline & & & Range & $\mathrm{MIC}_{90}$ & & & \\
\hline Enterobacterales & 3007 & NAm (2014-15) & $\leq 0.002-8$ & 0.5 & $\mathrm{NR}^{\mathrm{e}}$ & NR & [73] \\
\hline Enterobacterales & 3080 & EU (2014-15) & $\leq 0.002-8$ & I & NR & NR & [73] \\
\hline Enterobacterales & 2470 & NAm (20I5) & $\leq 0.002-128$ & 0.5 & NR & NR & {$[74]$} \\
\hline Enterobacterales & 3543 & EU (2015) & $\leq 0.002-8$ & I & NR & NR & {$[74]$} \\
\hline Enterobacterales & 20,949 & Cumulative (2014-16) & $\leq 0.002->256$ & NR & 99.4 & 98.6 & [7I] \\
\hline P. aeruginosa & 1530 & NAm/EU (2014-I5) & $\leq 0.002-8$ & 0.5 & NR & NR & [73] \\
\hline P. aeruginosa & 1540 & NAm/EU (2015) & $\leq 0.002-8$ & 0.5 & NR & NR & {$[74]$} \\
\hline P. aeruginosa & 4942 & Cumulative (2014-16) & $\leq 0.002-8$ & 2 & 99.9 & NR & {$[7 I]$} \\
\hline A. baumannii & 1148 & NAm/EU (2014-15) & $\leq 0.002-64$ & I & NR & NR & [73] \\
\hline Acinetobacter spp. & 308 & NAm (20I5) & $\leq 0.002->256$ & I & NR & NR & {$[74]$} \\
\hline Acinetobacter spp. & 664 & EU (2015) & $\leq 0.002->256$ & 2 & NR & NR & {$[74]$} \\
\hline A. baumannii & 2896 & Cumulative (2014-16) & $\leq 0.002-256$ & 2 & 95.6 & NR & [7I] \\
\hline S. maltophilia & 152 & NAm (2014-15) & $\leq 0.002-4$ & 0.5 & 100 & NR & [73] \\
\hline S. maltophilia & 276 & EU (2014-15) & $0.004-2$ & 0.25 & 100 & 100 & [73] \\
\hline S. maltophilia & 165 & NAm (2015) & $0.004-64$ & 0.5 & NR & NR & {$[74]$} \\
\hline S. maltophilia & 175 & EU (2015) & $\leq 0.002-64$ & 0.25 & NR & NR & [74] \\
\hline S. maltophilia & 217 & Global (2014-16) & $0.004-2$ & 0.25 & 100 & 100 & {$[28]$} \\
\hline S. maltophilia & 1173 & Cumulative (2014-16) & $\leq 0.002-64$ & 0.25 & 99.8 & 99.6 & [7I] \\
\hline B. cepacia complex & 40 & NAm (20I5) & $\leq 0.002-32$ & 0.5 & NR & NR & {$[74]$} \\
\hline B. cepacia complex & 49 & EU (20I5) & $\leq 0.002-32$ & 0.12 & NR & NR & [74] \\
\hline B. cepacia complex & 164 & Cumulative (2014-16) & $\leq 0.002-64$ & 0.25 & 95.7 & NR & [7I] \\
\hline Enterobacterales Carba-NS & 1020 & Global (2014-16) & $0.004-32$ & 4 & NR & NR & {$[28]$} \\
\hline Enterobacterales KPC+ & 75 & NAm/EU (2014-15) & $0.03-4$ & 2 & NR & NR & {$[75]$} \\
\hline Enterobacterales $\mathrm{KPC}-2^{+}$ & 355 & NR & $\leq 0.03-32$ & 8 & NR & NR & [76] \\
\hline Enterobacterales KPC- $3^{+}$ & 380 & NR & $\leq 0.03-64$ & 2 & NR & NR & {$[76]$} \\
\hline Enterobacterales OXA- $48^{+}$ & 154 & Global (2000-16) & $0.03-64$ & 2 & NR & NR & [77] \\
\hline $\begin{array}{l}\text { Enterobacterales MBL } \\
\text { (VIM, NDM, IMP) }^{+}\end{array}$ & 69 & Global $(2000-11)$ & $\leq 0.12->16$ & 16 & 89.8 & 86.9 & {$[78]$} \\
\hline $\begin{array}{l}\text { Enterobacterales MBL } \\
\left(^{(V I M, ~ N D M, ~ I M P) ~}\right.\end{array}$ & 134 & Global $(2000-16)$ & $0.03-64$ & 4 & NR & NR & [77] \\
\hline Enterobacterales ESCR & 2547 & Cumulative (2014-16) & NR & NR & 99.1 & 91.3 & {$[7 I]$} \\
\hline $\begin{array}{l}\text { P. aeruginosa Carba-NS } \\
\text { and CTZ-NS }\end{array}$ & 1005 & Global (2014-16) & $0.004-32$ & 4 & NR & NR & [28] \\
\hline P. aeruginosa Carba-NS & 1154 & Cumulative (2014-16) & NR & NR & 99.9 & 98.5 & [7I] \\
\hline $\begin{array}{l}\text { P. aeruginosa Carba-NS } \\
\mathrm{MBL}^{+}\end{array}$ & 30 & NAm/EU (2014-15) & $0.008-2$ & 2 & NR & NR & {$[75]$} \\
\hline $\begin{array}{l}\text { A. baumannii Carba-NS } \\
\text { OXA-23/24/58 }\end{array}$ & 681 & NAm/EU (2014-15) & $\leq 0.002-64$ & I & NR & NR & {$[75]$} \\
\hline A. baumannii Carba-NS & 1891 & Cumulative (2014-16) & NR & NR & 94.8 & 91.8 & [7I] \\
\hline
\end{tabular}

Notes: ${ }^{a}$ Carba-NS, carbapenem nonsusceptible; CTZ-NS, ceftolozane-tazobactam nonsusceptible; ESCR, resistant to expanded-spectrum cephalosporins (cefepime MIC >4 mg/ L). ${ }^{b} \mathrm{NAm}$, North America; EU, Europe. ${ }^{\mathrm{c} C L S I}$ susceptibility breakpoint for Enterobacterales, P. aeruginosa, Acinetobacter spp., and S. maltophilia. ${ }^{\mathrm{d}}$ EUCAST susceptibility breakpoint for Enterobacterales and $P$. aeruginosa. ${ }^{\mathrm{e}} \mathrm{NR}$, not reported.

into urine was of $60-70 \%$. The pharmacokinetic characteristics of cefiderocol at the dose of $2000 \mathrm{mg} \mathrm{q} 8 \mathrm{~h}$ over $1 \mathrm{~h}$ in healthy subjects are summarized in Table $2 .^{31}$
The pharmacokinetics of cefiderocol was compared in healthy subjects with those in subjects with mild [estimated glomerular filtration rate (eGFR) $60-<90 \mathrm{~mL} / \mathrm{min} /$ 
Table 2 Dosage Regimens of Cefiderocol Focused at Achieving $90 \%$ of PTAs of $75 \%$ T $>$ MIC Against Pathogens with an MIC UP to $4 \mathrm{mg} / \mathrm{L}$ in Patients with Different Classes of Renal Function ${ }^{44}$

\begin{tabular}{|l|l|}
\hline CLCr & Dosage Regimen \\
\hline$\geq 120 \mathrm{~mL} / \mathrm{min}^{\circ}$ (ARC) & $2 \mathrm{~g} \mathrm{q} 6 \mathrm{~h}$ over $3 \mathrm{~h}$ \\
$\geq 90 \mathrm{~mL} / \mathrm{min} / 1.73 \mathrm{~m}^{2^{*}}$ & $2 \mathrm{~g} q 8 \mathrm{~h}$ over $3 \mathrm{~h}$ \\
$60-<90 \mathrm{~mL} / \mathrm{min} / 1.73 \mathrm{~m}^{2^{*}}$ & $2 \mathrm{~g} q 8 \mathrm{~h}$ over $3 \mathrm{~h}$ \\
$30-<60 \mathrm{~mL} / \mathrm{min} / 1.73 \mathrm{~m}^{2^{*}}$ & $1.5 \mathrm{~g} \mathrm{q} 8 \mathrm{~h}$ over $3 \mathrm{~h}$ \\
15 to $30 \mathrm{~mL} / \mathrm{min} / 1.73 \mathrm{~m}^{2^{*}}$ & $1 \mathrm{gq} 8 \mathrm{~h}$ over $3 \mathrm{~h}$ \\
$<15 \mathrm{~mL} / \mathrm{min} / 1.73 \mathrm{~m}^{2^{*}}$ & $0.75 \mathrm{~g} \mathrm{q} / 2 \mathrm{~h}$ over $3 \mathrm{~h}$ \\
IHD & $0.75 \mathrm{~g} \mathrm{q} / 2 \mathrm{~h}$ over $3 \mathrm{~h}$ \\
\hline
\end{tabular}

Notes: ${ }^{\circ}$ Estimated by means of the Cockcroft and Gault formula. *Estimated by means of the modified diet renal diseases (MDRD) formula. **A supplemental dose of $0.75 \mathrm{~g}$ over $3 \mathrm{~h}$ should be administered after completion of IHD on the dialysis day. Abbreviations: ARC, augmented renal clearance; $C L C r$, creatinine clearance; IHD, intermittent hemodialysis.

$1.73 \mathrm{~m}^{2}$ ], moderate (eGFR $30-<60 \mathrm{~mL} / \mathrm{min} / 1.73 \mathrm{~m}^{2}$ ) and severe impairment of renal function (eGFR $<30 \mathrm{~mL} / \mathrm{min} /$ $1.73 \mathrm{~m}^{2}$ ) after a single dose of $1000 \mathrm{mg} .{ }^{32}$ Overall, total drug clearance and elimination half-life were inversely and linearly related with renal dysfunction. The mean ratio of drug exposure, in terms of area under the concentrationtime curve from zero-to-infinity $\left(\mathrm{AUC}_{0-\infty}\right)$, in subjects with mild, moderate, and severe renal impairment compared with those with normal renal function was 1.0, 1.5, and 2.5. The volume of distribution $(\mathrm{Vd})$ and the fraction unbound (fu) to the plasma proteins were very similar between groups (mean Vd ranged from 13.5 to $16.4 \mathrm{~L}$; mean fu ranged from 0.42 to 0.35 ). ${ }^{32}$

The potential for drug-drug interaction of cefiderocol with different human drug transporters [organic anion transporter (OAT) 1 and 3, organic cation transporter (OCT) 1 and 2, multidrug and toxin extrusion (MATE) 2-K and organic anion transporting polypeptide (OATP) 1B3] was assessed in three cohorts of healthy subjects. ${ }^{33}$ Substrates of these transporters were administered concomitantly to cefiderocol for assessing whether cefiderocol might or not inhibit drug transport. Overall, the study did not show any clinically significant drug-drug interaction of cefiderocol via drug transporters. ${ }^{33}$

The intrapulmonary pharmacokinetics of cefiderocol was assessed in healthy adult subjects after administration of a single $2000 \mathrm{mg}$ dose infused over $1 \mathrm{~h}^{34}$ The mean epithelial lining fluid (ELF)-to-plasma ratio was of 0.101 and 0.239 based on total drug in plasma and on free drug in plasma, respectively, similar to other cephalosporins. ${ }^{34}$

A recent study assessed the concentration-time profile of total radioactivity equivalent and unchanged cefiderocol after administration of $1000 \mathrm{mg}\left[{ }^{14} \mathrm{C}\right]$ cefiderocol over 1 $\mathrm{h}$ in healthy subjects. ${ }^{35}$ The findings showed that cefiderocol accounted for $92.3 \%$ of total radioactivity in plasma and for $90.6 \%$ of the administered dose into urine, thus confirming that metabolism is a minor route of elimination of cefiderocol. ${ }^{35}$

\section{Pharmacodynamic Properties}

Cefiderocol is a beta-lactam antibiotic for which the pharmacodynamic determinant of efficacy is the time that the plasma concentration exceeds the MIC of the pathogen $(\mathrm{t}>\mathrm{MIC})$ during the dosing interval. ${ }^{36}$ Experimental animal models of infections showed that a $>\mathrm{MIC}$ of around $75 \%$ is associated with an effective microbiological response to cefiderocol in terms of 1-2 log of bacterial killing. ${ }^{36,37}$ In a P. aeruginosa neutropenic murine model, the $\mathrm{t}>\mathrm{MIC}$ targets needed for stasis, $1 \log$ and $2 \log$ decrease in bacterial burden against strains with MICs of $0.064-0.5 \mathrm{mg} / \mathrm{L}$ ranged $44.4-94.7 \%, 50.2-97.5 \%$, and $62.1-100 \%$, respectively. ${ }^{36}$ In murine thigh and lung infection models, the mean $\mathrm{t}>\mathrm{MIC}$ needed for 1-log reduction in bacterial burden against various Gram-negative bacteria (E. coli, K. pneumoniae, $P$. aeruginosa, A. baumannii, and S. maltophilia) differed according to the site of infection and to the pathogen. ${ }^{37}$ In the thigh infection model, the mean $\mathrm{t}>\mathrm{MIC}$ was of $73.3 \%$ and $77.2 \%$ against Enterobacterales and P. aeruginosa, respectively; in the lung infection model, it was of $64.4 \%, \quad 70.3 \%, \quad 88.1 \%$, and $53.9 \%$ against Enterobacterales, $P$. aeruginosa, A. baumannii, and S. maltophilia, respectively.

Matsumoto et al assessed in an immunocompetent rat respiratory tract infection model the influence that infusion time of administration ( $3 \mathrm{~h}$ vs $1 \mathrm{~h}$ ) may have on the efficacy of humanized cefiderocol exposure ( $2 \mathrm{~g}$ q8h) against carbapenem-resistant Gram-negative bacilli (P. aeruginosa, $A$. baumannii and $K$. pneumoniae). Administration by extended infusion (EI) over 3 $\mathrm{h}$ resulted in more sustained reduction in lung bacterial burden (3.04-4.41 $\log _{10}$ ) compared with intermittent infusion (II) over $1 \mathrm{~h}\left(0.7-3.7 \log _{10}\right) .{ }^{38}$ This provided the rationale for considering the use of EI for ameliorating $\mathrm{t}>\mathrm{MIC}$ with cefiderocol.

Consistently, the efficacy of humanized exposures of $2 \mathrm{~g}$ q8h EI over $3 \mathrm{~h}$ cefiderocol was assessed against various species of Gram-negative bacteria with variable patterns of susceptibility to other antibiotics in several murine neutropenic thigh infection models. ${ }^{39-43}$ Monogue 
and colleagues assessed the efficacy of cefiderocol against a collection of 15 P. aeruginosa, A. baumannii, and Enterobacterales isolates. They found that the humanized exposures of cefiderocol were able to cause a $\geq 1$-log drop in bacterial burden against all pathogens with an MIC up to $4 \mathrm{mg} / \mathrm{L} .{ }^{42}$ Similar findings were observed also by Ghazi and colleagues who assessed the efficacy of humanized exposures of cefiderocol against eight different strains of P. aeruginosa with an MIC ranging from 0.063 to $0.5 \mathrm{mg} /$ $\mathrm{L}$ for cefiderocol, from 2 to $64 \mathrm{mg} / \mathrm{L}$ for cefepime, and from 1 to $32 \mathrm{mg} / \mathrm{L}$ for levofloxacin. ${ }^{40}$ Stainton and colleagues assessed the sustainability of humanized exposure of cefiderocol over $72 \mathrm{~h}$ against a collection of 12 P. aeruginosa, A. baumannii, and Enterobacterales isolates. Sustained kill was observed at $72 \mathrm{~h}$ against 9 out of 11 strains with an MIC ranging from 0.5 and $8 \mathrm{mg} / \mathrm{L}$, and no adaptive resistance was observed during therapy. ${ }^{43}$ In another study, the effect of cefiderocol human-simulated exposures was compared with that of ceftazidime humansimulated exposures ( $2 \mathrm{~g}$ q8h over $2 \mathrm{~h}$ ) against 24 S. maltophilia strains that were fully susceptible to cefiderocol (MICs $0.015-0.5 \mathrm{mg} / \mathrm{L}$ ) and either ceftazidimesusceptible (10/24) or ceftazidime-nonsusceptible (14/24). For cefiderocol bacterial killing was potent against all strains (mean \pm SD bacterial burden $\log _{10}$ reduction at 24 $\mathrm{h}-2.76 \pm 0.68 ; \geq 2 \log$ in $87.5 \%$ and $\geq 1 \log$ in the remaining $12.5 \%$ of isolates) whereas for ceftazidime it was present but less potent against the 10 ceftazidimesusceptible strains $(-1.38 \pm 1.49)$ and absent against the 14 ceftazidime-nonsusceptible strains (mean \pm SD bacterial growth of $0.64 \pm 0.79) .{ }^{39}$ Recently, a neutropenic thigh infection model confirmed that the efficacy of humanized cefiderocol exposure at $72 \mathrm{~h}$ against Enterobacterales, $P$. aeruginosa, and $A$. baumannii isolates is unaltered even by host iron overload (mean \pm SD $\log _{10}$ bacterial decrease $-2.5 \pm 1.5$ vs $-2.5 \pm 1.4$ in standard and ironoverloaded models, respectively). ${ }^{41}$ Consistently with these findings, the dosage regimens proposed for cefiderocol were focused at predicting by means of Monte Carlo simulations a high probability of success ( $\geq 90 \%$ of PTAs of $75 \% \mathrm{t}>\mathrm{MIC}$ ) against pathogens with an MIC up to $4 \mathrm{mg} / \mathrm{L}$ in patients belonging to all of the different classes of renal function (Table 2). ${ }^{44}$

Noteworthy is that cefiderocol is one of the few antibiotics in the therapeutic armamentarium with a welldefined dosing strategy specified in the manufacturer's fact sheet also for patients with augmented renal clearance (ARC). ARC is defined as a CLCr $>120-130 \mathrm{~mL} / \mathrm{min} /$
$1.73 \mathrm{~m}^{2}$ and is a pathophysiological condition that may accelerate the elimination of beta-lactams like cefiderocol, thus theoretically causing underexposure if standard dosages are administered. ${ }^{45}$ The strategy of a more intensified dosage is extremely relevant in preventing the risk of therapeutic failure associated with drug underexposure when using cefiderocol in populations of critically ill patients at high prevalence of ARC, like those with febrile neutropenia (16.4\%), sepsis (39.5-56\%), burns $(65 \%)$, trauma (85\%), and subarachnoid hemorrhage $(100 \%) .{ }^{45}$

The strategy of administering cefiderocol by EI among all patients irrespective of the degree of renal function may be helpful also at minimizing the development of multidrug antimicrobial resistance. Administering beta-lactams by EI rather than by II may represent a step forward in suppressing resistance amplification, as it may ensure better exposures in terms of $\mathrm{t}>\mathrm{MIC}$ compared with II. $^{46}$

\section{Results of Randomized Clinical Trials: Efficacy}

The efficacy of cefiderocol in complicated urinary tract infections (cUTI) was evaluated in a randomized (2:1), Phase II, double-blind, parallel-group, non-inferiority trial (APEKS-cUTI), started in 2014. In this trial, cefiderocol was compared with imipenem-cilastatin. Patients infected by carbapenem-resistant organisms were not enrolled. The primary endpoint was clinical cure/microbiological eradication (as a composite endpoint) at the test of cure (TOC), which was set at $7 \pm 2$ days after the end of treatment (EOT). The study was planned with a noninferiority margin of $20 \%$. However, following discussion with the FDA on the possible decrease of the noninferiority margin to $15 \%$ and the increase of the sample size, the study protocol was amended accordingly. ${ }^{47}$

The APEKS-cUTI study was conducted in 67 hospitals in 15 countries, from February 2015 to August 2016. Only individuals aged $\geq 18$ years and with a diagnosis of cUTI (with or without pyelonephritis) or acute uncomplicated pyelonephritis (30\% of the total sample size) were recruited. A one/two-week intravenous therapy was planned in the study protocol: cefiderocol $(2 \mathrm{~g}) \mathrm{q} 8 \mathrm{~h}$ vs imipenem-cilastatin (1g) q8h. Dosages were adjusted depending on renal function and body weight. The high dose of imipenem was chosen to allow inclusion of patients with $P$. aeruginosa infection.

A total of 371 patients were enrolled in the primary study population (modified intention-to-treat [mITT]). 
More than half of patients were aged $\geq 65$ years (in both arms) and complicated patients were more frequent than in contemporary studies. The most frequent uropathogens were E. coli and $K$. pneumoniae, whereas $P$. aeruginosa was isolated from $7 \%$ and $4 \%$ of patients treated with cefiderocol and imipenem-cilastatin, respectively. Several bacterial isolates were resistant to cefepime and levofloxacin. The primary endpoint was achieved by $73 \%(183 /$ 252 ) and $55 \%(65 / 119)$ of the patients enrolled in the cefiderocol and imipenem-cilastatin arms, respectively (adjusted difference: $18.6 \%$; 95\% confidence interval [CI] 8.2 to 28.9 , thereby demonstrating not only noninferiority but also superiority of cefiderocol as a post hoc result). When analyzing the single components of the composite endpoint, microbiological response was higher in patients treated with cefiderocol (73\% [184/252]) as opposed to those treated with imipenem-cilastatin $(56 \%$ [67/119]), with an adjusted difference of $17.3 \%$ (95\% CI 6.9 to 27.6). Conversely, clinical response was similar in the two arms (90\% [226/252] in cefiderocol-treated patients vs $87 \%$ [104/119] in the imipenem-cilastatin treated-patients; adjusted difference $2.4 \%, 95 \%$ CI -4.7 to 9.4$)$.

The efficacy of cefiderocol in patients with hospitalacquired bacterial pneumoniae (HABP), ventilator-associated bacterial pneumonia (VABP), or healthcare-associated bacterial pneumonia (HCABP) caused by GNB was evaluated in the study APEKS-NP, a Phase III, double-blind, randomized, noninferiority trial. The results of the APEKS-NP trial have been recently published. ${ }^{48,49}$ The patients were randomized to cefiderocol $2 \mathrm{~g}$ every $8 \mathrm{~h}$ or to meropenem $2 \mathrm{~g}$ every $8 \mathrm{~h}$, both as a 3-h infusion. Linezolid was administered in both arms for a duration of at least 5 days while cefiderocol or meropenem was administered for 7-14 days. The primary endpoint was all-cause mortality at day 14 for the mITT population, with a non-inferiority margin of $12.5 \%$. Cefiderocol was noninferior to meropenem with respect to all-cause mortality at day $14(12.4 \%$ [18/145] in cefiderocol arm vs $11.6 \%$ [17/ $146]$ in meropenem arm; difference $0.8 \%$; $95 \% \mathrm{CI}-6.6$ to $8.2)^{48}$

The CREDIBLE-CR study was an open-label, international, multicenter, Phase 3 RCT that was pathogenoriented rather than indication oriented: ${ }^{50,51}$ this was a descriptive study, not powered for inferential testing. Indeed, cefiderocol was compared with best available therapy (BAT) for the treatment of severe infections (HCABP, HABP, VABP, cUTI, or bloodstream infections
[BSI]/sepsis) due to carbapenem-resistant (CR) GNB. The results of the CREDIBLE-CR study have also been recently published. ${ }^{52}$ Cefiderocol $2 \mathrm{~g}$ every $8 \mathrm{~h}$ was given as a 3-h infusion and BAT was chosen by the investigator and consisted of up to three antibiotics. Patients were randomized 2:1 to receive cefiderocol or BAT. Duration of therapy (either with cefiderocol or with BAT) was 7 to 14 days, possibly extended up to 21 days based on reasonable explanation. In patients with cUTI, a minimum length of therapy of 5 days was allowed. The primary efficacy endpoint for patients with $\mathrm{HABP} / \mathrm{VABP} / \mathrm{HCABP}$ and for those with $\mathrm{BSI} /$ sepsis was clinical cure at TOC visit. For patients with cUTI, the primary efficacy endpoint was microbiological cure (eradication) at TOC. In the CR-mITT population (primary study population) clinical cure rates at TOC were comparable between groups, overall (52.5\% [42/80] in cefiderocol-treated vs 50\% [19/38] in BAT-treated patients) and in subgroups of patients with HABP/VABP/HCABP $(50 \%$ [20/40] in cefiderocol-treated vs 52.6\% [10/19] in BATtreated patients), and patients with BSI/sepsis (43.5\% [10/ 23 ] in cefiderocol-treated vs $42.9 \%$ [6/14] in BAT-treated patients). Microbiological cure in patients with cUTI was $52.9 \%(9 / 17)$ and $20 \%(1 / 5)$ in cefiderocol-treated and BAT-treated patients, respectively. However, all-cause mortality at day 14 , day 28 , and day 49 was numerically higher in the cefiderocol group $(19 \%, 25 \%, 34 \%$, respectively) compared to BAT $(12 \%, 18 \%, 18 \%$, respectively). This mortality imbalance was greatest at days 14,28 , and 49 for patients with HABP/VABP/HCABP (cefiderocol $24 \%, 31 \%$, and $42 \%$ vs BAT $14 \%, 18 \%$, and $18 \%$ ). It is worth noting that, in the safety population, a greater number of deaths occurring up to day 3 were reported in the cefiderocol arm (cefiderocol 4\% vs 0\% BAT), which may be considered unrelated to study drug efficacy. Moreover, a greater number of deaths were reported in the cefiderocol arm (9\% cefiderocol vs 0\% BAT) after day 28 through the end of study as opposed to BAT, whereas proportions were similar from day 4 to day 28 (21\% and $18 \%$ in cefiderocol and BAT arms, respectively).

Of note, the difference in 49-day mortality stratified for pathogen was the highest for Acinetobacter spp. (50\% [21/ 42] vs $18 \%$ [3/17] in cefiderocol and BAT-treated patients, respectively), although it is of note that some variables indicating severity of presentation or of baseline diseases (ICU at randomization, severe renal dysfunction, ongoing shock, and shock within 31 days before randomization) 
were more frequent in the cefiderocol than BAT arms in patients with Acinetobacter spp. infections. ${ }^{52}$

\section{Safety of Cefiderocol}

Two Phase 1 studies showed mild, clinically not significant adverse events mainly represented by diarrhea and skin reactions (maculopapular rash, urticarial) in less than $20 \%$ of patients, with only one treatment discontinuation due to urticaria. ${ }^{31,32}$ In another phase 1 study in healthy adult subjects, cefiderocol in normal doses $(2 \mathrm{~g})$ and supratherapeutic doses (3-4 g) had no apparent clinically significant effect on QT and corrected QT (QTcF) interval. ${ }^{53}$

Phase 2 and phase 3 studies confirmed that cefiderocol is comparable to other cephalosporins in terms of tolerability and safety profile. In the APEKS-cUTI RCT, safety was assessed in all randomly assigned individuals who received at least one dose of study drug. ${ }^{47}$ Adverse events occurred in $41 \%(122 / 300)$ and $51 \%(76 / 148)$ of patients in the cefiderocol and in the imipenem-cilastatin groups, respectively, with the majority being mild or moderate. Overall, diarrhea and constipation were observed in $7.7 \%$ of patients in the cefiderocol group and in $10.1 \%$ of those in the imipenem-cilastatin group. Serious adverse events were reported in $5 \%$ and $8 \%$ of patients in the cefiderocol and imipenem-cilastatin groups, respectively. Among serious adverse events, Clostridioides difficile infection (CDI) occurred in one patient in the cefiderocol group and in two patients in the imipenem-cilastatin group. One death due to cardiac arrest, considered unrelated to study drug by the investigator, was reported in the cefiderocol group.

In the APEKS-NP study, adverse events were observed in $88 \%(130 / 148)$ and $86 \%(129 / 150)$ in cefiderocol and meropenem groups, respectively. ${ }^{48}$ In both arms, urinary tract infections (15.5\% and $10.7 \%$ in cefiderocol and meropenem arms, respectively) and hypokalemia (10.8\% and $15.3 \%$ in cefiderocol and meropenem arms, respectively) were the most frequently observed adverse events. Serious adverse events were observed in 36\% (54/148, of which 3 drug-related) and 30\% (45/150, of which 5 drug-related) in cefiderocol and meropenem groups, respectively. Among patients treated with cefiderocol and meropenem, 4/148 (3\%) and 4/150 (3\%) developed C. difficile infection. ${ }^{48}$

According to the results of the CREDIBLE-CR study, the rate of adverse events (evaluated in 101 patients who received cefiderocol and 49 patients who received BAT) was similar in the two arms, with over $90 \%$ of patients experiencing at least one adverse event. ${ }^{52}$ Diarrhea, pyrexia, septic shock, vomiting, and hypokalemia were the most frequently observed adverse events in both groups and diarrhea (19\% vs $12 \%)$, ALT increased $(7 \%$ vs $0 \%$ ), AST increased ( $8 \%$ vs $2 \%$ ), pleural effusion ( $8 \%$ vs $2 \%$ ), and chest pain ( $6 \%$ vs $0 \%$ ) were observed more frequently in the cefiderocol than in the BAT groups. The majority of chest pain episodes reported in the cefiderocol group were considered to be of non-cardiovascular origin and not related to cefiderocol. Most adverse events occurred at a low frequency and were considered manifestations of the patients' underlying disease. Indeed, the frequency of adverse events considered to be treatmentrelated by the investigator was $15 \%(15 / 101)$ in the cefiderocol arm and 22\% (11/49) in the BAT arm. Diarrhea (2\%), abnormal liver function tests (2\%), ALT increased (3\%), and AST increased (3\%) were the most frequently reported treatment-related, treatment-emergent adverse events in the cefiderocol group; while acute kidney injury $(8 \%)$ was the most frequently reported treatment-related, treatment-emergent adverse event in the BAT group. Serious adverse events were reported for $50 \%$ and $47 \%$ of patients in cefiderocol group and BAT group, respectively. Septic shock was the most frequently reported serious adverse event in both cefiderocol (12\%) and BAT (12\%) groups. Overall, only 1/101 patient in the cefiderocol group (1\%) experienced a treatment-related serious adverse event, that is, an increase in transaminases levels which led to study drug discontinuation and resolved in 30 days. Conversely, treatment-related serious adverse events were observed in 5/49 patients in the BAT group (10\%). Discontinuation due to treatment-related adverse events occurred in $3 \%$ and $4 \%$ of patients in the cefiderocol group and BAT group, respectively.

\section{Case Reports and Case Series}

Case reports and case series of patients with severe GNB infections treated with cefiderocol in compassionate use are detailed in Table $3 .^{54-66}$ All these cases highlight unique challenges in managing patients infected by MDRGNB including MBL-producing GNB.

\section{Place in Therapy}

Cefiderocol is a first-in-class antibiotic, a siderophore intravenous cephalosporin that binds ferric iron and is actively transported into the periplasm of GNB. ${ }^{14,67,68}$ Beyond its novel mechanism of action, from a practical standpoint what makes it attractive for clinicians is the 
Table 3 Published Case Reports and Case Series of Compassionate Use of Cefiderocol

\begin{tabular}{|c|c|c|c|c|}
\hline $\begin{array}{l}\text { Age, Sex } \\
\text { (Reference) }\end{array}$ & $\begin{array}{l}\text { Underlying Condition of the } \\
\text { Patient }\end{array}$ & $\begin{array}{l}\text { Type of Infection Pathogen } \\
\text { (in vitro Susceptibility) }\end{array}$ & Antimicrobial Therapy History & Outcome \\
\hline 46, $\mathrm{Male}^{57}$ & $\begin{array}{l}\text { Partial right great toe amputation treated } \\
\text { with daptomycin and levofloxacin for } \\
\text { a vancomycin-resistant Enterococcus } \\
\text { faecium and Pseudomonas aeruginosa stump } \\
\text { infection with residual osteomyelitis. } \\
\text { Hemodialysis-dependent for end-stage } \\
\text { renal disease, diabetes mellitus, coronary } \\
\text { disease. }\end{array}$ & $\begin{array}{l}\text { Perforation of the colon with } \\
\text { intraabdominal abscess. End } \\
\text { ileostomy and right hemicolectomy. } \\
\text { Pseudomonas aeruginosa (carbapenem- } \\
\text { resistant, cefiderocol susceptible), } \\
\text { Escherichia coli, Bacteroides fragilis. }\end{array}$ & $\begin{array}{l}\text { First line: Meropenem, daptomycin, } \\
\text { linezolid. } \\
\text { Second line: Ceftazidime/avibactam, } \\
\text { polymyxin B, metronidazole. polymyxin } \\
\text { B was discontinued due to suspect of } \\
\text { neurotoxicity. } \\
\text { Third line: cefiderocol plus } \\
\text { metronidazole. }\end{array}$ & $\begin{array}{l}\text { Decrease in size of intraabdominal } \\
\text { abscess on day } 5 \text { of cefiderocol } \\
\text { therapy. } \\
\text { Complete resolution of paracolic } \\
\text { gutter abscess on day } 19 \text { of therapy. } \\
\text { Discontinuation of treatment after } 28 \\
\text { days therapy. }\end{array}$ \\
\hline Adult, male ${ }^{58}$ & $\begin{array}{l}\text { Severe HINI influenza complicated } \\
\text { by bilateral pneumonia and } \\
\text { respiratory failure. } \\
\text { Intubation and extracorporeal } \\
\text { membrane oxygenation. }\end{array}$ & $\begin{array}{l}\text { Bacteremia. } \\
\text { Acinetobacter baumannii (extensively } \\
\text { drug-resistant, susceptible to colistin); } \\
\text { Klebsiella pneumoniae (carbapenem } \\
\text { resistant; colistin, gentamicin, } \\
\text { ceftazidime/avibactam, and } \\
\text { cefiderocol susceptible). }\end{array}$ & $\begin{array}{l}\text { First line empiric: piperacillin- } \\
\text { tazobactam, clarithromycin, linezolid, } \\
\text { zanamivir. } \\
\text { Second line: meropenem, } \\
\text { vancomycin, anidulafungin. } \\
\text { Third line: colistin, fosfomycin, } \\
\text { tigecycline, daptomycin. Fourth line: } \\
\text { cefiderocol, linezolid }\end{array}$ & $\begin{array}{l}\text { Patient conditions rapidly improved } \\
\text { with resolution of fever and } \\
\text { normalization of procalcitonin levels } \\
\text { after start of cefiderocol therapy. } \\
\text { After } 14 \text { days of cefiderocol } \\
\text { treatment, chest X-rays showed } \\
\text { complete resolution of lung infiltrates. }\end{array}$ \\
\hline 78, female $^{56}$ & $\begin{array}{l}\text { Hydronephrosis secondary to } \\
\text { a spontaneous ureteric hematoma. } \\
\text { She had a past medical history of } \\
\text { aortic stenosis, ischemic heart } \\
\text { disease, and cerebral infarction and } \\
\text { was in remission from breast cancer. } \\
\text { Thickened aortic valve. }\end{array}$ & $\begin{array}{l}\text { Bacteremia complicated by aortic valve } \\
\text { endocarditis, Pseudomonas aeruginosa } \\
\text { (susceptible only to colistin, gentamicin and } \\
\text { amikacin); (resistant also to ceftazidime/ } \\
\text { avibactam and ceftolozane/tazobactam. } \\
\text { No synergy between antipseudomonal } \\
\text { agents and fosfomycin and rifampicin). }\end{array}$ & $\begin{array}{l}\text { First line: colistin plus gentamicin. } \\
\text { Second line: colistin plus } \\
\text { meropenem } \\
\text { Third line: colistin plus meropenem } \\
\text { plus cefiderocol for one week } \\
\text { followed by colistin plus cefiderocol } \\
\text { for an additional } 3 \text { weeks. }\end{array}$ & $\begin{array}{l}\text { Aortic valve replacement was } \\
\text { performed on day } 2 \text { of cefiderocol. } \\
\text { Blood culture taken the day of } \\
\text { surgery was negative and persisted } \\
\text { negative up to day } 275 .\end{array}$ \\
\hline 68, female $^{55}$ & $\begin{array}{l}\text { End-stage renal disease secondary to } \\
\text { diabetes who had been on } \\
\text { hemodialysis for } 8 \text { years. Renal } \\
\text { transplant complicated by cardiac } \\
\text { arrest with pulseless electronic } \\
\text { activity, requiring initiation of } \\
\text { extracorporeal membrane } \\
\text { oxygenation and continuous renal } \\
\text { replacement therapy. Hematoma } \\
\text { surrounding the kidney allograft and } \\
\text { placement of abdominal drains }\end{array}$ & $\begin{array}{l}\text { Isolation from peritoneal drain } \\
\text { cultures and blood. } \\
\text { Klebsiella pneumoniae positive for both } \\
\text { NDM-I and OXA-48 group enzymes } \\
\text { (resistant to carbapenems, } \\
\text { ceftazidime/avibactam, meropenem/ } \\
\text { vaborbactam, and gentamycin; } \\
\text { susceptible to colistin, tigecycline, } \\
\text { eravacycline, and cefiderocol). }\end{array}$ & $\begin{array}{l}\text { First line: polymyxin B plus } \\
\text { tigecycline. } \\
\text { Second line: polymyxin B, } \\
\text { ceftazidime/avibactam, aztreonam. } \\
\text { Third line: polymyxin B, } \\
\text { ceftazidime/avibactam, cefiderocol } \\
(1.5 \mathrm{~g} / / 2 \mathrm{~h})\end{array}$ & $\begin{array}{l}\text { Subsequent blood cultures and peritoneal } \\
\text { fluid culture were all negative after } \\
\text { cefiderocol was started, with clinical } \\
\text { improvement. The patient developed } \\
\text { vancomycin-resistant Enterococcus faecium } \\
\text { bacteremia, invasive candidiasis due to } \\
\text { Candida glabrata, and Clostridioides difficile- } \\
\text { infection, which were treated with } \\
\text { daptomycin, caspofungin, and oral } \\
\text { vancomycin, respectively. } \\
\text { Eventually the patient developed fatal } \\
\text { ischemic colitis. }\end{array}$ \\
\hline I5, male ${ }^{54}$ & $\begin{array}{l}\text { Femur fracture after a motor vehicle } \\
\text { accident, intramedullary pin } \\
\text { placement. }\end{array}$ & $\begin{array}{l}\text { Recurrent wound infection treated } \\
\text { with various antibiotics (details not } \\
\text { available). Chronic osteomyelitis of } \\
\text { the left femur, with phlegmonous } \\
\text { changes extending to the skin. } \\
\text { Pseudomonas aeruginosa (extensively } \\
\text { drug resistant, susceptible only to } \\
\text { colistin and cefiderocol), Extended- } \\
\text { spectrum } \beta \text {-lactamases-producing } \\
\text { Klebsiella pneumoniae (susceptible to } \\
\text { carbapenem, ceftazidime/avibactam, } \\
\text { colistin, cefiderocol, } \\
\text { aminoglycosides). }\end{array}$ & $\begin{array}{l}\text { First line empiric: levofloxacin, } \\
\text { metronidazole, trimethoprim- } \\
\text { sulfamethoxazole, antibiotic-cement } \\
\text { nail containing tobramycin and } \\
\text { vancomycin. } \\
\text { Second line: cefepime, vancomycin, } \\
\text { metronidazole. } \\
\text { Third line: ceftazidime/avibactam } \\
\text { plus aztreonam } \\
\text { Fourth line: polymyxin B, } \\
\text { aztreonam, tigecycline. } \\
\text { Fifth line: cefiderocol plus } \\
\text { aztreonam. Aztreonam discontinued } \\
\text { after two weeks. Bone graft and } \\
\text { antibiotic nail exchange. Cefiderocol } \\
\text { was administered for a total of } 14 \\
\text { weeks. }\end{array}$ & $\begin{array}{l}\text { After } 9 \text { weeks of cefiderocol therapy } \\
\text { bone cultures were sterile, and } \\
\text { a histopathology report showed } \\
\text { benign bone without associated acute } \\
\text { or chronic inflammation. }\end{array}$ \\
\hline
\end{tabular}


Table 3 (Continued).

\begin{tabular}{|c|c|c|c|c|}
\hline $\begin{array}{l}\text { Age, Sex } \\
\text { (Reference) }\end{array}$ & $\begin{array}{l}\text { Underlying Condition of the } \\
\text { Patient }\end{array}$ & $\begin{array}{l}\text { Type of Infection Pathogen } \\
\text { (in vitro Susceptibility) }\end{array}$ & Antimicrobial Therapy History & Outcome \\
\hline $84, \mathrm{male}^{59}$ & $\begin{array}{l}\text { Diabetes mellitus, chronic renal } \\
\text { failure, previous non-Hodgkin's } \\
\text { lymphoma, vascular diseases, hallux } \\
\text { amputation. }\end{array}$ & $\begin{array}{l}\text { BSI secondary to an infected, wet } \\
\text { gangrenous left foot, caused by OXA- } \\
\text { and NDM-producing K. pneumoniae } \\
\text { (susceptible to colistin, tigecycline, } \\
\text { and cefiderocol). }\end{array}$ & $\begin{array}{l}\text { First line empiric: piperacillin- } \\
\text { tazobactam, clindamycin, and } \\
\text { amikacin, in addition to surgical } \\
\text { debridement } \\
\text { Second line: colistin, tigecycline } \\
\text { Third line: cefiderocol plus colistin, } \\
\text { then de-escalated to cefiderocol } \\
\text { monotherapy. Treated with } \\
\text { cefiderocol for } 14 \text { days }\end{array}$ & $\begin{array}{l}\text { Improvement and discharge from } \\
\mathrm{ICU} \text {, subsequent death in a medical } \\
\text { ward without signs of infection } \\
\text { relapse }\end{array}$ \\
\hline $63, \mathrm{male}^{60}$ & $\begin{array}{l}\text { Obesity, diabetes mellitus, cardiac } \\
\text { ischemic disease, gout arthritis. }\end{array}$ & $\begin{array}{l}\text { Para-duodenal pancreatic collection } \\
\text { with extensively drug resistant (XDR) } \\
\text { P. aeruginosa (susceptible to colistin } \\
\text { and cefiderocol) isolated from } \\
\text { pancreatic pus. }\end{array}$ & $\begin{array}{l}\text { First line: colistin, meropenem } \\
\text { Second line: cefiderocol }\end{array}$ & $\begin{array}{l}\text { Favorable resolution after } 6 \text { weeks of } \\
\text { treatment. Subsequent isolation of } \\
\text { a cefiderocol-resistant strain from } \\
\text { ischial eschar. Subsequent death due } \\
\text { to XDR P. aeruginosa pneumonia }\end{array}$ \\
\hline $\begin{array}{l}65, \text { male } \\
70, \text { female } \\
56, \text { female }^{61}\end{array}$ & $\begin{array}{l}\text { Patient I: hypertension, cardiac } \\
\text { tamponade, septic thrombosis due to } \\
\text { carbapenemase-producing } \\
\text { K. pneumoniae } \\
\text { Patient 2: diabetes mellitus, K. oxytoca } \\
\text { septic shock } \\
\text { with bacteraemic pyelonephritis } \\
\text { Patient 3: Staphylococcus aureus spinal } \\
\text { implant infection. }\end{array}$ & $\begin{array}{l}\text { Patient I: BSI due to pan-drug } \\
\text { resistant Acinetobacter baumannii } \\
\text { Patient 2: BSI due to colistin- } \\
\text { susceptible Acinetobacter baumannii, } \\
\text { complicated by XDR P. aeruginosa } \\
\text { bacteremia } \\
\text { Patient 3: wound } \\
\text { superinfection and spondylodiscitis } \\
\text { due to XDR A. baumannii (bone } \\
\text { culture positive) }\end{array}$ & $\begin{array}{l}\text { Patient I: } \\
\text { First line empiric: trimethoprim/ } \\
\text { sulfamethoxazole } \\
\text { Second line: cefiderocol } \\
\text { Patient 2: } \\
\text { First line: colistin } \\
\text { Second line: cefiderocol } \\
\text { Patient 3: } \\
\text { First line: colistin, tigecycline } \\
\text { Second line: cefiderocol }\end{array}$ & $\begin{array}{l}\text { Patient I: } \\
\text { Improvement and discharge from } \\
\text { ICU, subsequent death in a medical } \\
\text { ward without signs of infection } \\
\text { relapse } \\
\text { Patient 2: } \\
\text { Resolution of A. baumannii but not } \\
\text { P. aeruginosa BSI. Subsequent death } \\
\text { due to intercurrent HSV-I } \\
\text { disseminated infection } \\
\text { Patient 3: Bone culture negative after } \\
2 I \text { days of cefiderocol treatment. } \\
\text { Subsequent completion of a 6-week } \\
\text { treatment with oral minocycline and } \\
\text { no signs of relapse at 9-week follow- } \\
\text { up }\end{array}$ \\
\hline $\begin{array}{l}10 \text { patients } \\
(4 \text { males and } \\
6 \text { females) } \\
\text { with a mean } \\
\text { age of } 69 \\
\text { years } \\
62\end{array}$ & $\begin{array}{l}\text { Hypertension }(9 / 10) \text {, COVID-19 }(5 / \\
10) \text {, burns }(4 / 10) \text {, obesity }(2 / 10) \text {, } \\
\text { bipolar disorder }(1 / 10) \text {, bladder } \\
\text { cancer }(1 / 10) \text {, colonic perforation ( } 1 / \\
10) \text {, intravenous drug use }(1 / 10) \text {. }\end{array}$ & $\begin{array}{l}\text { Six BSI and } 4 \text { ventilator-associated } \\
\text { pneumonia (VAP) due carbapenem- } \\
\text { resistant organisms (7 A. baumannii, I } \\
\text { NDM-producing Stenotrophomonas } \\
\text { maltophilia, I NDM-producing } \\
\text { K. pneumoniae, I A. baumannii plus } \\
\text { NDM-producing K. pneumoniae) }\end{array}$ & $\begin{array}{l}\text { First line: } 7 \text { colistin-based } \\
\text { combination, I colistin monotherapy, } \\
\text { I tigecycline plus ampicillin- } \\
\text { sulbactam, I ceftazidime/avibactam } \\
\text { plus aztreonam plus fosfomycin } \\
\text { Second line: cefiderocol ( } 9 \\
\text { monotherapy, I combined with } \\
\text { fosfomycin) }\end{array}$ & $\begin{array}{l}\text { Clinical outcome at day } 30 \text { was } \\
\text { favorable in } 7 / 10 \text { cases }(70 \%), 30 \text {-day } \\
\text { mortality was } 10 \%(1 / 10)\end{array}$ \\
\hline $67, \mathrm{male}^{63}$ & $\begin{array}{l}\text { Atrial fibrillation, chronic Glaucoma, } \\
\text { previous left knee replacement, aortic } \\
\text { stent, right knee replacement. }\end{array}$ & $\begin{array}{l}\text { Acute prosthetic joint infection of the } \\
\text { right knee managed with } \\
\text { debridement, antibiotics and implant } \\
\text { retention (DAIR). Isolation from } \\
\text { intraoperative material of XDR } \\
\text { Enterobacter hormaechei (susceptible } \\
\text { to colistin and tigecycline). }\end{array}$ & $\begin{array}{l}\text { First line empirical: vancomycin, } \\
\text { piperacillin/tazobactam } \\
\text { Second line: colistin, tigecycline } \\
\text { Third line: cefiderocol }\end{array}$ & $\begin{array}{l}\text { Improved, discharged, and treated for } \\
12 \text { weeks (including } 10 \text { weeks of } \\
\text { cefiderocol monotherapy). Follow-up } \\
\text { at } 12 \text { weeks after end of antibiotic } \\
\text { treatment showed full recovery. }\end{array}$ \\
\hline 45, female $^{64}$ & $\begin{array}{l}\text { Hemangioblastoma requiring multiple } \\
\text { neurosurgical interventions, } \\
\text { esophageal-pleural fistula, esophageal } \\
\text { perforation repaired with } \\
\text { jejunostomy and gastrostomy tube } \\
\text { placement. }\end{array}$ & $\begin{array}{l}\text { Esophageal leak with fistula and } \\
\text { growth of cefiderocol-susceptible } \\
\text { XDR P. aeruginosa from plural fluid } \\
\text { culture, treated surgically and with } \\
\text { antibiotic therapy. }\end{array}$ & $\begin{array}{l}\text { First line: ceftazidime/avibactam, } \\
\text { polymyxin B } \\
\text { Second line: cefiderocol }\end{array}$ & $\begin{array}{l}\text { Full recovery after } 3 \text { weeks of } \\
\text { cefiderocol treatment. Subsequent } \\
\text { respiratory colonization by } \\
\text { cefiderocol-resistant XDR } \\
\text { P. aeruginosa, without infection and } \\
\text { need for antibiotic therapy. }\end{array}$ \\
\hline
\end{tabular}

(Continued) 
Table 3 (Continued).

\begin{tabular}{|c|c|c|c|c|}
\hline $\begin{array}{l}\text { Age, Sex } \\
\text { (Reference) }\end{array}$ & $\begin{array}{l}\text { Underlying Condition of the } \\
\text { Patient }\end{array}$ & $\begin{array}{l}\text { Type of Infection Pathogen } \\
\text { (in vitro Susceptibility) }\end{array}$ & Antimicrobial Therapy History & Outcome \\
\hline $\begin{array}{l}29, \text { male } \\
64, \text { male } \\
62, \text { male }^{65}\end{array}$ & $\begin{array}{l}\text { Patient I: polytrauma with external } \\
\text { fixation of an open fracture of the } \\
\text { tibia } \\
\text { Patient 2: polytrauma } \\
\text { Patient 3: blunt thoracic trauma with } \\
\text { lung injury, hemothorax, rib fractures. }\end{array}$ & $\begin{array}{l}\text { Patient I: early postoperative, } \\
\text { polymicrobial, implant-associated } \\
\text { wound infection due to VIM- } \\
\text { producing P. aeruginosa, OXA-23- } \\
\text { producing A. baumannii, and KPC- } \\
\text { producing Enterobacter cloacae } \\
\text { Patient 2: postoperative implant- } \\
\text { associated spine infection due to } \\
\text { OXA-40 and NDM- producing } \\
\text { A. baumannii } \\
\text { Patient 3: pleural empyema due to } \\
\text { XDR A. baumannii and subsequent } \\
\text { acute osteomyelitis and urinary tract } \\
\text { infection due to XDR A. baumannii. }\end{array}$ & $\begin{array}{l}\text { Patient I: } \\
\text { Treatment: multiple surgeries plus } \\
\text { cefiderocol for } 2 \text { weeks and colistin } \\
\text { and ceftazidime-avibactam for } 4 \\
\text { weeks } \\
\text { Patient 2: } \\
\text { Treatment: removal of } \\
\text { osteosynthesis and colistin plus } \\
\text { cefiderocol for } 14 \text { days, then } \\
\text { cefiderocol monotherapy for a total } \\
\text { of } 6 \text { weeks } \\
\text { Patient } 3 \text { : } \\
\text { Treatment: cefiderocol plus colistin } \\
\text { (for } 14 \text { days) for pleural empyema } \\
\text { and cefiderocol ( } 6 \text { weeks) for } \\
\text { osteomyelitis }\end{array}$ & $\begin{array}{l}\text { Patient I: } \\
\text { Definite implantation and not signs of } \\
\text { relapse at } 8 \text { weeks of follow-up } \\
\text { Patient 2: } \\
\text { Novel osteosynthesis with no signs of } \\
\text { relapse at } 13 \text { weeks of follow-up } \\
\text { Patient 3: } \\
\text { No signs of relapse at } 6 \text { weeks of } \\
\text { follow-up }\end{array}$ \\
\hline 57, male $^{66}$ & $\begin{array}{l}\text { Hypertension, diabetes mellitus, left } \\
\text { tibia and fibula fracture with external } \\
\text { fixation followed by two surgical } \\
\text { debridements. }\end{array}$ & $\begin{array}{l}\text { Osteomyelitis of left leg with } \\
\text { intraoperative cultures positive for } \\
\text { Enterococcus faecalis, Corynebacterium } \\
\text { striatum, And XDR A. baumannii. }\end{array}$ & $\begin{array}{l}\text { First line empirical: piperacillin/ } \\
\text { tazobactam with subsequent addition } \\
\text { of vancomycin } \\
\text { Second line: Polymyxin B, } \\
\text { minocycline, and vancomycin (the } \\
\text { latter subsequently substituted by } \\
\text { daptomycin) } \\
\text { Third line: Daptomycin, } \\
\text { meropenem, tigecycline } \\
\text { Fourth line: Daptomycin, } \\
\text { cefiderocol }\end{array}$ & $\begin{array}{l}\text { Cefiderocol discontinued after } 102 \\
\text { days and no signs of relapse at } 128 \\
\text { days after antibiotics discontinuation. }\end{array}$ \\
\hline
\end{tabular}

displayed in vitro activity against carbapenem-resistant A. baumannii and MBL-producing GNB, ie, those MDRGNB for which there are currently no marketed active $\beta$ lactams (without forgetting its in vitro activity against Stenotrophomonas spp. and Burkholderia spp.). ${ }^{69}$ Therefore, clinical data from both registrative studies and post-marketing experiences are essential to confirm whether these promises from in vitro studies could readily translate into clinical practice, as well as to delineate a precise place in therapy for cefiderocol for the treatment of MDR-GNB in the near future. Real-life data would also be important for further delineating the safety of cefiderocol through Phase 4 surveillance studies.

While the results of the APEKS-cUTI and APEKSNP studies have eventually led to the FDA approval of cefiderocol for cUTI and HABP/VABP, ${ }^{4,48}$ the recent EMA approval of cefiderocol for the treatment of infections due to Gram-negative bacteria in adults with limited treatment options ${ }^{70,71}$ opens doors to its use also for other pressing priorities, such as BSI caused by carbapenem- resistant A. baumannii or MBL producers, or for its empirical use in endemic settings or in colonized patients with severe infection. In this regard, it would be critical to clarify the remaining issue of the increased mortality in cefiderocol-treated patients in the CREDIBLE-CR study, especially in the case of infections due to nonfermenting GNB. In our opinion, this could be achieved in two different, complementary ways: (i) through conduction of further RCT (the open-label GAMECHANGER RCT, which is comparing cefiderocol vs BAT for the treatment of BSI due to GNB, is currently recruiting patients [NCT03869437]); (ii) through postmarketing observational experiences, which, although unable to provide high-quality evidence for guiding treatment due to the inherent limitations of observational studies (even when properly adjusting for confounding variables) may provide useful hypothesis-generating data and clinical success/mortality rates for fine-tuning the design of future RCT (perhaps by identifying those categories of patients that may benefit the most from 
cefiderocol administration) should also the GAMECHANGER study provide inconclusive evidence.

Until then, some uncertainties in delineating the precise place in therapy of cefiderocol for the treatment of MDRGNB infections will remain. Indeed, on the one hand, we now have a $\beta$-lactam that, at least in vitro, fills the gaps against some high-priority MDR-GNB, taking also into account the consideration that the increased mortality observed in the CREDIBLE-CR study may be merely due to chance alone in view of the low power related to the small sample size (especially in subgroups) of the CREDIBLE-CR study and the current lack of a clear explanation for the observed result. On the other hand, further studies remain necessary to verify this hypothesis, and cefiderocol should not be used indiscriminately. In our opinion, the potential advantages of having restored $\beta$-lactam activity against highly resistant $A$. baumannii and MBL producers should not be wasted while waiting for further evidence. What remains largely unclear is whether cefiderocol should be used alone or in combination with BAT (eg, polymyxins) until more solid evidence is provided. There is still no clear answer to this question, which, notably, does not involve the classical (and still unresolved) dilemma of the general comparison of monotherapy vs combinations for MDR-GNB infections in terms of efficacy, but the novel one of not using cefiderocol alone considering the possible imbalance in mortality registered in the CREDIBLE-CR study. In our opinion, it could be ultimately reasonable to consider using cefiderocol-including combinations in the case of severe clinical presentations, in which a de-escalation rather than escalation strategy could be more indicated (authors opinion only, not supported by published evidence at the present time). The same may apply to the inclusion of cefiderocol in empirical regimens in patients with severe infections and hospital-level or patient-level risk factors for infections due to carbapenem-resistant $A$. baumannii and/or MBL producers. Of note, in this scenario reliable and rapid microbiological tests for the detection of causative agents and involved resistance mechanisms will increasingly play a crucial role in the optimization of the empirical use of cefiderocol (initiation/discontinuation) according to antimicrobial and diagnostic stewardship principles. ${ }^{72}$

In conclusion, cefiderocol expands the spectrum of MDR-GNB that can be treated again with $\beta$-lactams and will likely offer a precious addition to the clinician armamentarium. Because of this unique potential, it remains essential to provide both RCT (eg, GAMECHANGER) and real-life data to improve the clinicians' ability to exploit its benefit in both empirical and targeted treatment of MDR-GNB infections.

\section{Acknowledgments}

This research was conducted on behalf of ISGRI-SITA (Italian Study Group on Resistant Infections of the Italian Society of Anti-infective Therapy).

\section{Funding}

This work was funded by an unrestricted grant by Shionogi Srl. The sponsor had no role in selecting the participants, reviewing the literature, defining recommendations, drafting the paper, or in the decision to submit the manuscript for publication. All views expressed are solely those of the authors.

\section{Disclosure}

Outside the submitted work, DRG reports honoraria from Stepstone Pharma $\mathrm{GmbH}$ and unconditional grants from MSD Italia and Correvio Italia.

FP reports grants from Shionogi, during the conduct of the study; personal fees from Angelini, Basilea Pharmaceutica, Gilead, Hikma, Merck Sharp \& Dohme, Nordic Pharma, Novartis, Shionogi, Thermo Fisher, and Sandoz, outside the submitted work. Outside the submitted work, he has participated in advisory boards and/or received speaker honoraria from Angelini, Basilea Pharmaceutica, Correvio, Gilead, Hikma, Merck Sharp \& Dohme, Novartis, Sanofi Aventis, and Thermo-Fisher.

GMR reports grants, personal fees from Shionogi, during the conduct of the study; grants, personal fees, nonfinancial support from Accelerate and Menarini; grants from Angelini, bioMérieux, Cepheid, Elitech, Merck, Nordic Pharma, Seegene, Zambon, Symcel, DID, Hain Lifescience $\mathrm{GmbH}$, GenePoc, Setlance, Biomedical Service, Qvella, and Qlinea, outside the submitted work; personal fees from Becton Dickinson, Angelini, bioMérieux, Cepheid, Merck, Nordic Pharma, Pfizer, Venatorx, Zambon, Roche, Thermo Fisher, Beckman Coulter, Qpex, and Qiagen, outside the submitted work.

CT reports personal fees from Correvio, Basilea, Hikma, MSD, Pfizer, Thermo Fisher, Zambon, Biomerieux, and Shionogi, and personal fees from Angelini, outside the submitted work. Outside the submitted work, he has received research grants, and/or been a consultant and/or received a fee for speaking from bioMérieux, Zambon, Basilea, Merck, Nordic Pharma, Angelini, Thermo Fisher, Biotest, Pfizer, Astra Zeneca, Shionogi, Hikma, Avir Pharma, Biotest. 
MT reports personal honoraria for participating in advisory boards and/or for meeting presentations from Angelini, Astellas, Menarini, MSD, Nordic Pharma, Pfizer, Roche, Shionogi, outside the submitted work.

MB reports grants and personal fees from Shionogi, outside the submitted work. Outside the submitted work, he has participated in advisory boards and/or received speaker honoraria from Achaogen, Angelini, Astellas, Bayer, Basilea, BioMérieux, Cidara, Gilead, Menarini, MSD, Nabriva, Paratek, Pfizer, Roche, Melinta, Shionogi, Tetraphase, VenatoRx and Vifor and has received study grants from Angelini, Basilea, Astellas, Shionogi, Cidara, Melinta, Gilead, Pfizer and MSD.

\section{References}

1. Giani T, Arena F, Pollini S, et al. Italian nationwide survey on Pseudomonas aeruginosa from invasive infections: activity of ceftolozane/tazobactam and comparators, and molecular epidemiology of carbapenemase producers. $J$ Antimicrob Chemother. 2018;73:664-671. doi:10.1093/jac/dkx453

2. Kadri SS, Adjemian J, Lai YL, et al. Difficult-to-treat resistance in Gram-negative Bacteremia at 173 US Hospitals: retrospective cohort analysis of prevalence, predictors, and outcome of resistance to all first-line agents. Clin Infect Dis. 2018;67:1803-1814.

3. Munoz-Price LS, Poirel L, Bonomo RA, et al. Clinical epidemiology of the global expansion of Klebsiella pneumoniae carbapenemases. Lancet Infect Dis. 2013;13:785-796. doi:10.1016/S1473-3099(13)70190-7

4. Theuretzbacher U. Global antimicrobial resistance in Gram-negative pathogens and clinical need. Curr Opin Microbiol. 2017;39:106-112. doi:10.1016/j.mib.2017.10.028

5. Bassetti M, Giacobbe DR, Giamarellou H, et al. Management of KPC-producing Klebsiella pneumoniae infections. Clin Microbiol Infect. 2018;24:133-144. doi:10.1016/j.cmi.2017.08.030

6. Bassetti M, Peghin M, Vena A, Giacobbe DR. Treatment of infections due to MDR Gram-negative bacteria. Front Med. 2019;6:74. doi:10.3389/fmed.2019.00074

7. Panidis D, Markantonis SL, Boutzouka E, et al. Penetration of gentamicin into the alveolar lining fluid of critically ill patients with ventilator-associated pneumonia. Chest. 2005;128:545-552. doi:10.1378/chest.128.2.545

8. Tsuji BT, Pogue JM, Zavascki AP, et al. International Consensus Guidelines for the Optimal Use of the Polymyxins: endorsed by the American College of Clinical Pharmacy (ACCP), European Society of Clinical Microbiology and Infectious Diseases (ESCMID), Infectious Diseases Society of America (IDSA), International Society for Anti-infective Pharmacology (ISAP), Society of Critical Care Medicine (SCCM), and Society of Infectious Diseases Pharmacists (SIDP). Pharmacotherapy. 2019;39:10-39.

9. Giacobbe DR, Bassetti M, De Rosa FG, et al. Ceftolozane/tazobactam: place in therapy. Expert Rev Anti Infect Ther. 2018;16:307-320. doi:10.1080/14787210.2018.1447381

10. Pogue JM, Bonomo RA, Kaye KS. Ceftazidime/avibactam, meropenem/ vaborbactam, or both? Clinical and formulary considerations. Clin Infect Dis. 2019;68:519-524. doi:10.1093/cid/ciy576

11. Tumbarello M, Trecarichi EM, Corona A, et al. Efficacy of ceftazidime-avibactam salvage therapy in patients with infections caused by klebsiella pneumoniae carbapenemase-producing $\mathrm{K}$. pneumoniae. Clin Infect Dis. 2019;68:355-364. doi:10.1093/cid/ ciy 492
12. Zhanel GG, Lawrence CK, Adam H, et al. Imipenem-relebactam and meropenem-vaborbactam: two novel carbapenem-beta-lactamase inhibitor combinations. Drugs. 2018;78:65-98. doi:10.1007/s40265017-0851-9

13. Yamano Y. In vitro activity of cefiderocol against a broad range of clinically important gram-negative bacteria. Clin Infect Dis. 2019;69: S544-S551. doi:10.1093/cid/ciz827

14. Zhanel GG, Golden AR, Zelenitsky S, et al. Cefiderocol: a siderophore cephalosporin with activity against carbapenem-resistant and multidrug-resistant gram-negative bacilli. Drugs. 2019;79:271-289. doi:10.1007/s40265-019-1055-2

15. Ito A, Nishikawa T, Matsumoto S, et al. Siderophore cephalosporin cefiderocol utilizes ferric iron transporter systems for antibacterial activity against Pseudomonas aeruginosa. Antimicrob Agents Chemother. 2016;60:7396-7401.

16. Ito-Horiyama T, Ishii $\mathrm{Y}$, Ito A, et al. Stability of novel siderophore cephalosporin S-649266 against clinically relevant carbapenemases. Antimicrob Agents Chemother. 2016;60:4384-4386. doi:10.1128/ AAC.03098-15

17. Poirel L, Kieffer N, Nordmann P. Stability of cefiderocol against clinically significant broad-spectrum oxacillinases. Int $J$ Antimicrob Agents. 2018;52:866-867. doi:10.1016/j.ijantimicag.2018.11.005

18. Sato T, Yamawaki K. Cefiderocol: discovery, chemistry, and in vivo profiles of a novel siderophore cephalosporin. Clin Infect Dis. 2019;69:S538-S543. doi:10.1093/cid/ciz826

19. Ito ANT, Kuriowa M, Ishioka $Y$, et al. Mechanism of cefiderocol high MIC mutants obtained in non-clinical FoR studies. Presented at: ID Week 2018, Poster 696; San Francisco, CA.

20. Ito $A$, Sato $T$, Ota $M$, et al. In vitro antibacterial properties of cefiderocol, a novel siderophore cephalosporin, against gram-negative bacteria. Antimicrob Agents Chemother. 2018;62.

21. Moya B, Zamorano L, Juan C, et al. Affinity of the new cephalosporin CXA-101 to penicillin-binding proteins of Pseudomonas aeruginosa. Antimicrob Agents Chemother. 2010;54:3933-3937. doi:10.1128/AAC.00296-10

22. Ito A, Nishikawa T, Ota M, et al. Stability and low induction propensity of cefiderocol against chromosomal AmpC beta-lactamases of Pseudomonas aeruginosa and Enterobacter cloacae. J Antimicrob Chemother. 2018;73:3049-3052. doi:10.1093/jac/dky317

23. Kidd JM, Abdelraouf K, Nicolau DP. Development of neutropenic murine models of iron overload and depletion to study the efficacy of siderophore-antibiotic conjugates. antimicrob agents chemother. 2019;64. doi:10.1128/AAC.01961-19

24. Clinical and Laboratory Standards Institute. Performance standards for anti-microbial susceptibility testing, 30th informational supplement. CLSI supplement M100-Ed. 30. Wayne, PA: CLSI; 2020.

25. EUCAST clinical breakpoints cefiderocol addendum. Available from: https://www.eucast.org/fileadmin/src/media/PDFs/EUCAST_files/ Breakpoint_tables/Addenda/Cefiderocol_addendum_20200501.pdf. Accessed December 4, 2020.

26. Hackel MA, Tsuji M, Yamano Y, et al. Reproducibility of broth microdilution MICs for the novel siderophore cephalosporin, cefiderocol, determined using iron-depleted cation-adjusted Mueller-Hinton broth. Diagn Microbiol Infect Dis. 2019;94:321-325. doi:10.1016/j. diagmicrobio.2019.03.003

27. FDA website. Available from: https://www.fda.gov/drugs/develop ment-resources/cefiderocol-injection. Accessed December 4, 2020.

28. Hackel MA, Tsuji M, Yamano Y, et al. In vitro activity of the siderophore cephalosporin, cefiderocol, against carbapenem-nonsusceptible and multidrug-resistant isolates of gram-negative bacilli collected worldwide in 2014 to 2016. Antimicrob Agents Chemother. 2018;62.

29. Kohira N, Hackel MA, Ishioka Y, et al. Reduced susceptibility mechanism to cefiderocol, a siderophore cephalosporin, among clinical isolates from global surveillance program (SIDERO-WT-2014). $J$ Glob Antimicrob Resist. 2020;22:738-741. doi:10.1016/j. jgar.2020.07.009 
30. Rolston KVI, Gerges B, Shelburne S, et al. Activity of cefiderocol and comparators against isolates from cancer patients. Antimicrob Agents Chemother. 2020;64. doi:10.1128/AAC.01955-19

31. Saisho Y, Katsube T, White S, et al. Pharmacokinetics, safety, and tolerability of cefiderocol, a novel siderophore cephalosporin for gram-negative bacteria, in healthy subjects. Antimicrob Agents Chemother. 2018;62. doi:10.1128/AAC.02163-17

32. Katsube T, Echols R, Arjona Ferreira JC, et al. Cefiderocol, a siderophore cephalosporin for gram-negative bacterial infections: pharmacokinetics and safety in subjects with renal impairment. $J$ Clin Pharmacol. 2017;57:584-591. doi:10.1002/jcph.841

33. Katsube T, Miyazaki S, Narukawa Y, et al. Drug-drug interaction of cefiderocol, a siderophore cephalosporin, via human drug transporters. Eur J Clin Pharmacol. 2018;74:931-938. doi:10.1007/ s00228-018-2458-9

34. Katsube T, Saisho Y, Shimada J, Furuie H. Intrapulmonary pharmacokinetics of cefiderocol, a novel siderophore cephalosporin, in healthy adult subjects. $J$ Antimicrob Chemother. 2019;74:1971-1974. doi:10.1093/jac/dkz123

35. Miyazaki S, Katsube T, Shen H, et al. Metabolism, excretion, and pharmacokinetics of [(14) C]-cefiderocol (S-649266), a siderophore cephalosporin, in healthy subjects following intravenous administration. J Clin Pharmacol. 2019;59:958-967. doi:10.1002/ jcph. 1386

36. Ghazi IM, Monogue ML, Tsuji M, Nicolau DP. Pharmacodynamics of cefiderocol, a novel siderophore cephalosporin, in a Pseudomonas aeruginosa neutropenic murine thigh model. Int $J$ Antimicrob Agents. 2018;51:206-212. doi:10.1016/j.ijantimicag.2017.10.008

37. Nakamura R, Ito-Horiyama $T$, Takemura $M$, et al. In vivo pharmacodynamic study of cefiderocol, a novel parenteral siderophore cephalosporin, in murine thigh and lung infection models. Antimicrob Agents Chemother. 2019;63. doi:10.1128/AAC.02031-18

38. Matsumoto S, Singley CM, Hoover J, et al. Efficacy of cefiderocol against carbapenem-resistant gram-negative bacilli in immunocompetent-rat respiratory tract infection models recreating human plasma pharmacokinetics. Antimicrob Agents Chemother. 2017;61. doi:10.1128/AAC.00700-17

39. Chen IH, Kidd JM, Abdelraouf K, Nicolau DP. Comparative in vivo antibacterial activity of human-simulated exposures of cefiderocol and ceftazidime against stenotrophomonas maltophilia in the murine thigh model. Antimicrob Agents Chemother. 2019. doi:10.1128/ AAC.01558-19

40. Ghazi IM, Monogue ML, Tsuji M, Nicolau DP. Humanized exposures of cefiderocol, a siderophore cephalosporin, display sustained in vivo activity against siderophore-resistant Pseudomonas aeruginosa. Pharmacology. 2018;101:278-284.

41. Kidd JM, Abdelraouf K, Nicolau DP. Efficacy of humanized cefiderocol exposure is unaltered by host iron overload in the thigh infection model. Antimicrob Agents Chemother. 2019;64. doi:10.1128/ AAC.01767-19

42. Monogue ML, Tsuji M, Yamano Y, et al. Efficacy of humanized exposures of cefiderocol (S-649266) against a diverse population of gram-negative bacteria in a murine thigh infection model. Antimicrob Agents Chemother. 2017;61. doi:10.1128/AAC.01022-17

43. Stainton SM, Monogue ML, Tsuji M, et al. Efficacy of humanized cefiderocol exposures over 72 hours against a diverse group of gram-negative isolates in the neutropenic murine thigh infection model. Antimicrob Agents Chemother. 2019;63.

44. Katsube T, Wajima T, Ishibashi T, et al. Pharmacokinetic/pharmacodynamic modeling and simulation of cefiderocol, a parenteral siderophore cephalosporin, for dose adjustment based on renal function. Antimicrob Agents Chemother. 2017;61. doi:10.1128/AAC.01381-16

45. Cook AM, Hatton-Kolpek J. Augmented renal clearance. Pharmacotherapy. 2019;39:346-354. doi:10.1002/phar.2231
46. Ambrose PG, Lomovskaya O, Griffith DC, et al. beta-Lactamase inhibitors: what you really need to know. Curr Opin Pharmacol. 2017;36:86-93. doi:10.1016/j.coph.2017.09.001

47. Portsmouth S, van Veenhuyzen D, Echols R, et al. Cefiderocol versus imipenem-cilastatin for the treatment of complicated urinary tract infections caused by Gram-negative uropathogens: a phase 2, randomised, double-blind, non-inferiority trial. Lancet Infect Dis. 2018;18:1319-1328. doi:10.1016/S1473-3099(18)30554-1

48. Wunderink RG, Matsunaga Y, Ariyasu M, et al. Cefiderocol versus high-dose, extended-infusion meropenem for the treatment of Gram-negative nosocomial pneumonia (APEKS-NP): a randomised, double-blind, phase 3, non-inferiority trial. Lancet Infect Dis. 2020. doi:10.1016/S1473-3099(20)30731-3

49. Shionogi Inc. FDA accepts Shionogi's supplemental new drug application with priority review for FETROJA ${ }^{\circledR}$ (cefiderocol) for the treatment of hospital-acquired bacterial pneumonia and ventilatorassociated bacterial pneumonia; [cited August 12, 2020]. Available from: https://www.shionogi.com/us/en/news/2020/6/FDA-AcceptsShionogis-Supplemental-New-Drug-Application-with-PriorityReview-for-FETROJA.html. Accessed December 4, 2020.

50. Bassetti M, Ariyasu M, Binkowitz B, et al. Designing A pathogen-focused study to address the high unmet medical need represented by carbapenem-resistant gram-negative pathogens - the international, multicenter, randomized, open-label, Phase 3 CREDIBLE-CR Study. Infect Drug Resist. 2019;12:3607-3623.

51. Echols R, Ariyasu M, Nagata TD. Pathogen-focused clinical development to address unmet medical need: cefiderocol targeting carbapenem resistance. Clin Infect Dis. 2019;69:S559-S564. doi:10.1093/ $\mathrm{cid} / \mathrm{ciz} 829$

52. Bassetti M, Echols R, Matsunaga Y, et al. Efficacy and safety of cefiderocol or best available therapy for the treatment of serious infections caused by carbapenem-resistant Gram-negative bacteria (CREDIBLE-CR): a randomised, open-label, multicentre, pathogen-focused, descriptive, phase 3 trial. Lancet Infect Dis. 2020. doi:10.1016/S1473-3099(20)30796-9

53. Sanabria C, Migoya E, Mason JW, et al. Effect of cefiderocol, a siderophore cephalosporin, on QT/QTc interval in healthy adult subjects. Clin Ther. 2019;41:1724-1736 e1724.

54. Alamarat ZI, Babic J, Tran TT, et al. Long-term compassionate use of cefiderocol to treat chronic osteomyelitis caused by extensively drug-resistant Pseudomonas aeruginosa and extended-spectrum-betalactamase-producing klebsiella pneumoniae in a pediatric patient. Antimicrob Agents Chemother. 2020;64.

55. Contreras DA, Fitzwater SP, Nanayakkara DD, et al. Coinfections of two strains of NDM-1- and OXA-232-Coproducing Klebsiella pneumoniae in a kidney transplant patient. Antimicrob Agents Chemother. 2020;64.

56. Edgeworth JD, Merante D, Patel S, et al. Compassionate use of cefiderocol as adjunctive treatment of native aortic valve endocarditis due to extremely drug-resistant Pseudomonas aeruginosa. Clin Infect Dis. 2019;68:1932-1934. doi:10.1093/cid/ciy963

57. Stevens RW, Clancy M. Compassionate use of cefiderocol in the treatment of an intraabdominal infection due to multidrug-resistant Pseudomonas aeruginosa: a case report. Pharmacotherapy. 2019;39:1113-1118. doi:10.1002/phar.2334

58. Trecarichi EM, Quirino A, Scaglione V, et al. Successful treatment with cefiderocol for compassionate use in a critically ill patient with XDR Acinetobacter baumannii and KPC-producing Klebsiella pneumoniae: a case report. $J$ Antimicrob Chemother. 2019;74:3399-3401. doi:10.1093/jac/dkz318

59. Lampejo T, Cherian BP, Tan MGM, et al. Cefiderocol in the treatment of systemic carbapenemase-producing multi-drug resistant Klebsiella pneumoniae infection. J Glob Antimicrob Resist. 2020. doi:10.1016/j. jgar.2020.10.008 
60. Grande Perez C, Maillart E, Miendje Deyi VY, et al. Compassionate use of cefiderocol in a pancreatic abscess and emergence of resistance. Med Mal Infect. 2020. doi:10.1016/j.medmal.2020.10.022

61. Oliva A, Ceccarelli G, De Angelis M, et al. Cefiderocol for compassionate use in the treatment of complicated infections caused by extensively and pan-resistant Acinetobacter baumannii. $J$ Glob Antimicrob Resist. 2020;23:292-296. doi:10.1016/j.jgar.2020.09.019

62. Falcone M, Tiseo G, Nicastro M, et al. Cefiderocol as rescue therapy for Acinetobacter baumannii and other carbapenem-resistant Gram-Negative infections in ICU patients. Clin Infect Dis. 2020. doi: $10.1093 / \mathrm{cid} / \mathrm{ciaa} 1410$

63. Siméon S, Dortet L, Bouchand F, et al. Compassionate use of cefiderocol to treat a case of prosthetic joint infection due to extensively drug-resistant enterobacter hormaechei. Microorganisms. 2020;8:1236. doi:10.3390/microorganisms 8081236

64. Kufel WD, Steele JM, Riddell SW, et al. Cefiderocol for treatment of an empyema due to extensively drug-resistant Pseudomonas aeruginosa: clinical observations and susceptibility testing considerations. IDCases. 2020;21:e0863. doi:10.1016/j.idcr.2020.e00863

65. Zingg S, Nicoletti GJ, Kuster S, et al. Cefiderocol for extensively drug-resistant gram-negative bacterial infections: real-world experience from a case series and review of the literature. Open Forum Infect Dis. 2020;7:ofaa185. doi:10.1093/ofid/ofaa185

66. Dagher M, Ruffin F, Marshall S, et al. Case report: successful rescue therapy of extensively drug-resistant acinetobacter baumannii osteomyelitis with cefiderocol. Open Forum Infect Dis. 2020;7:ofaa150. doi:10.1093/ofid/ofaa150

67. Mollmann U, Heinisch L, Bauernfeind A, et al. Siderophores as drug delivery agents: application of the "Trojan Horse" strategy. Biometals. 2009;22:615-624. doi:10.1007/s10534-009-9219-2

68. Page MGP. The role of iron and siderophores in infection, and the development of siderophore antibiotics. Clin Infect Dis. 2019;69: S529-S537. doi:10.1093/cid/ciz825

69. Wu JY, Srinivas P, Pogue JM. Cefiderocol: a novel agent for the management of multidrug-resistant gram-negative organisms. Infect Dis Ther. 2020;9:17-40. doi:10.1007/s40121-020-00286-6

70. Fectroja. Summary of product characteristics; [cited August 15, 2020]. Available from: https://www.ema.europa.eu/en/documents/pro duct-information/fetcroja-epar-product-information_en.pdf. Accessed December 4, 2020.
71. Fetcroja EMA assessment report 27 February 2020. EMA/136096/2.

72. Giacobbe DR, Giani T, Bassetti M, et al. Rapid microbiological tests for bloodstream infections due to multidrug resistant Gram-negative bacteria: therapeutic implications. Clin Microbiol Infect. 2020;26:713-722. doi:10.1016/j.cmi.2019.09.023

73. Hackel MA, Tsuji M, Yamano Y, et al. In vitro activity of the siderophore cephalosporin, cefiderocol, against a recent collection of clinically relevant gram-negative bacilli from North America and Europe, including carbapenem-nonsusceptible isolates (SIDERO-WT-2014 Study). Antimicrob Agents Chemother. 2017;61. doi:10.1128/AAC.00093-17

74. Karlowsky JA, Hackel MA, Tsuji M, et al. In vitro activity of cefiderocol, a siderophore cephalosporin, against gram-negative bacilli isolated by clinical laboratories in North America and Europe in 2015-2016: SIDERO-WT-2015. Int J Antimicrob Agents. 2019;53:456-466. doi:10.1016/j.ijantimicag.2018.11.007

75. Kazmierczak KM, Tsuji M, Wise MG, et al. In vitro activity of cefiderocol, a siderophore cephalosporin, against a recent collection of clinically relevant carbapenem-non-susceptible Gram-negative bacilli, including serine carbapenemase- and metallo-beta-lactamaseproducing isolates (SIDERO-WT-2014 Study). Int J Antimicrob Agents. 2019;53:177-184.

76. Jacobs MR, Abdelhamed AM, Good CE, et al. ARGONAUT-I: activity of cefiderocol (S-649266), a siderophore cephalosporin, against gram-negative bacteria, including carbapenem-resistant nonfermenters and enterobacteriaceae with defined extended-spectrum beta-lactamases and carbapenemases. Antimicrob Agents Chemother. 2019;63.

77. Dobias J, Denervaud-Tendon V, Poirel L, Nordmann P. Activity of the novel siderophore cephalosporin cefiderocol against multidrug-resistant Gram-negative pathogens. Eur J Clin Microbiol Infect Dis. 2017;36:2319-2327. doi:10.1007/s10096-017-3063-z

78. Kohira N, West J, Ito A, et al. In vitro antimicrobial activity of a siderophore cephalosporin, S-649266, against enterobacteriaceae clinical isolates, including carbapenem-resistant strains. Antimicrob Agents Chemother. 2016;60:729-734. doi:10.1128/AAC.01695-15
Infection and Drug Resistance

\section{Publish your work in this journal}

Infection and Drug Resistance is an international, peer-reviewed openaccess journal that focuses on the optimal treatment of infection (bacterial, fungal and viral) and the development and institution of preventive strategies to minimize the development and spread of resistance. The journal is specifically concerned with the epidemiology of antibiotic resistance and the mechanisms of resistance development and diffusion in both hospitals and the community. The manuscript management system is completely online and includes a very quick and fair peerreview system, which is all easy to use. Visit http://www.dovepress.com/ testimonials.php to read real quotes from published authors. 